\title{
Chropowatość powierzchni papierowych i z tworzyw sztucznych po procesie uszlachetniania powierzchni
}

\author{
Paper and plastic roughness properties after surface \\ refinement processes
}

\section{Streszczenie}

Celem pracy była analiza wpływu procesu uszlachetniania na właściwości powierzchniowe papieru i folii polietylenowej. Analizie poddano podłoża niezadrukowane, zadrukowane i polakierowane.

Właściwości powierzchniowe uzyskanych powłok ocieniono mikroskopowo za pomocą profilometru skaningowego. Zbadano współczynniki chropowatości różnych materiałów.

Wykazano, że proces uszlachetniania powierzchni w istotny sposób zmienia jej gładkość.

Słowa kluczowe: farby wodorozcieńczalne; lakiery dyspersyjne; chropowatość powierzchni; profilometria skaningowa

\begin{abstract}
The objective of the research is to analyse the influence of the refinement processes on the paper and foil surface properties.

The surface properties of unprinted, printed, printed and varnished papers were evaluated with the 3D optical microscope. The surface roughness coefficients of different materials were calculated in the studies.

It was observed that the varnishing process significantly influences the surface roughness properties.
\end{abstract}

Keywords: water-based inks and varnishes; surface roughness; 3D optical microscope

\section{Wprowadzenie}

Gładkość powierzchni jest jednym z bardzo istotnych parametrów dotyczących materiałów drukowych, zarówno tych papierowych, jak i z tworzyw sztucznych. Gładkość podłoży papierowych zależy od formowania papieru, kalandrowania, liczby warstw powlekających, rodzaju i składu mieszanki powlekającej. Papiery powlekane charakteryzują się znacznie wyższą gładkością powierzchni niż papiery niepowlekane. Przyjmuje się, że im więcej warstw powlekających papier, tym bardziej gładka powierzchnia. Za papiery o wysokiej jakości uznaje się np. dwukrotnie lub trzykrotnie powlekane papiery drukowe. Materiały z tworzyw sztucznych charakteryzują się znacznie większą gładkością niż anizotropowe materiały papierowe. W artykule zajęto się głównie wpływem warstwy powlekającej, takiej jak farba czy lakier stosowanej w procesie drukowania na zmiany parametru gładkości powierzchni.

Zadrukowanie materiałów z tworzyw sztucznych jest przedmiotem wielu badań, w szczególności związanych z właściwościami użytkowymi czy zwilżalnością powierzchni $[3,6]$. W artykułach $[4,5]$ badano również chropowatość powierzchni, ale badania te realizowane były pod innym kątem niż przedstawione w niniejszym artykule.

\section{Materiały i urządzenia}

W badaniach zadrukowano papier powlekany błyszczący oraz aktywowaną folię polietylenową wodorozcieńczalną farbą fleksograficzną oraz trzema rodzajami lakierów o różnym połysku oznaczonymi, jako lakier 1, 2 i 3 z wykorzystaniem laboratoryjnych urządzeń:

- ręczny K-lox firmy RK Print użyty do wykonania wydruków i lakierowania próbek,

- cylinder rastrowy o liniaturze $80 \mathrm{l} / \mathrm{cm}$ i pojemności kałamarzyków $10,2 \mathrm{~cm}^{3} / \mathrm{m}^{2}$ do wykonywania wydruków,

- cylinder rastrowy o liniaturze $40 \mathrm{l} / \mathrm{cm}$ i pojemności kałamarzyków $39,1 \mathrm{~cm}^{3} / \mathrm{m}^{2}$ do lakierowania próbek,

- profilometr skaningowy Contour GT K1 3D firmy Bruker do oceny chropowatości powierzchni.

Metodykę wykonania próbek opisano we wcześniejszym artykule [1] oraz częściowo w artykule [2].

\section{Wyniki badań}

Na rysunku 1 zamieszczono trójwymiarowy obraz chropowatości powierzchni papierowej niezadrukowanej, na rysunku 2 zadrukowanej i polakierowanej lakierem nr 2 powierzchni

Dr inż. Marta Gajadhur - Politechnika Warszawska.

Autor korespondencyjny/Corresponding author. m.gajadhur@wip.pw.edu.pl 
papieru, natomiast na rysunku 3 trójwymiarowy obraz powierzchni folii PE zadrukowanej warstwą farby i również polakierowanego lakierem $\mathrm{nr} 2$.

$\mathrm{Na}$ podstawie uzyskanych wyników można stwierdzić, że lakier naniesiony na wyschniętą warstwę farby tworzy pofalowaną powierzchnię. Przyjmowanie farby przez papier czy folię, jak i lakieru przez farbę wiąże się z zależnościami adhezyjno-kohezyjnymi, jak również napięciem powierzchniowym materiałów. Można przypuszczać, że zaobserwowana pofalowana powierzchnia naniesionej farby czy lakieru

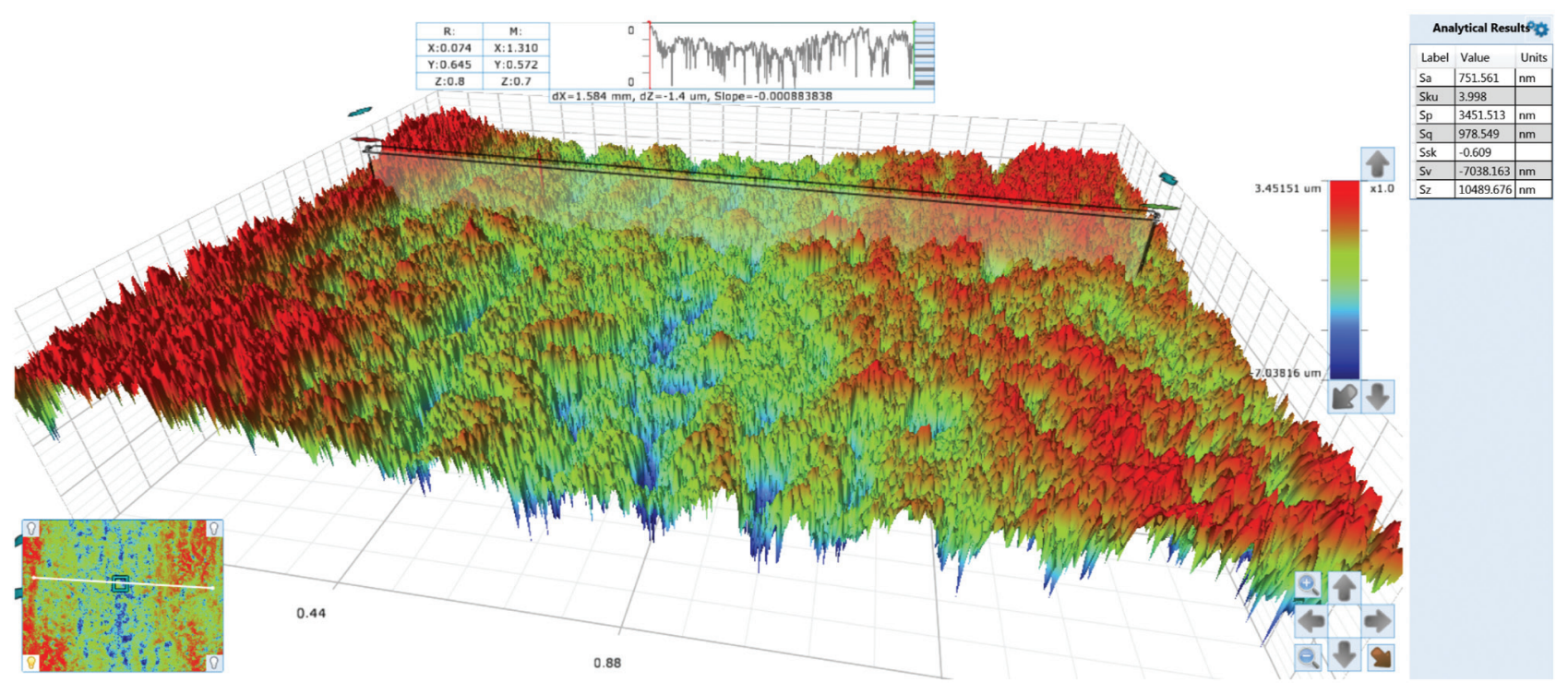

Rys. 1. Obraz 3D chropowatości powierzchni papieru powlekanego błyszczącego niezadrukowanego

Fig. 1. 3D image of the surface roughness of unprinted coated glossy paper

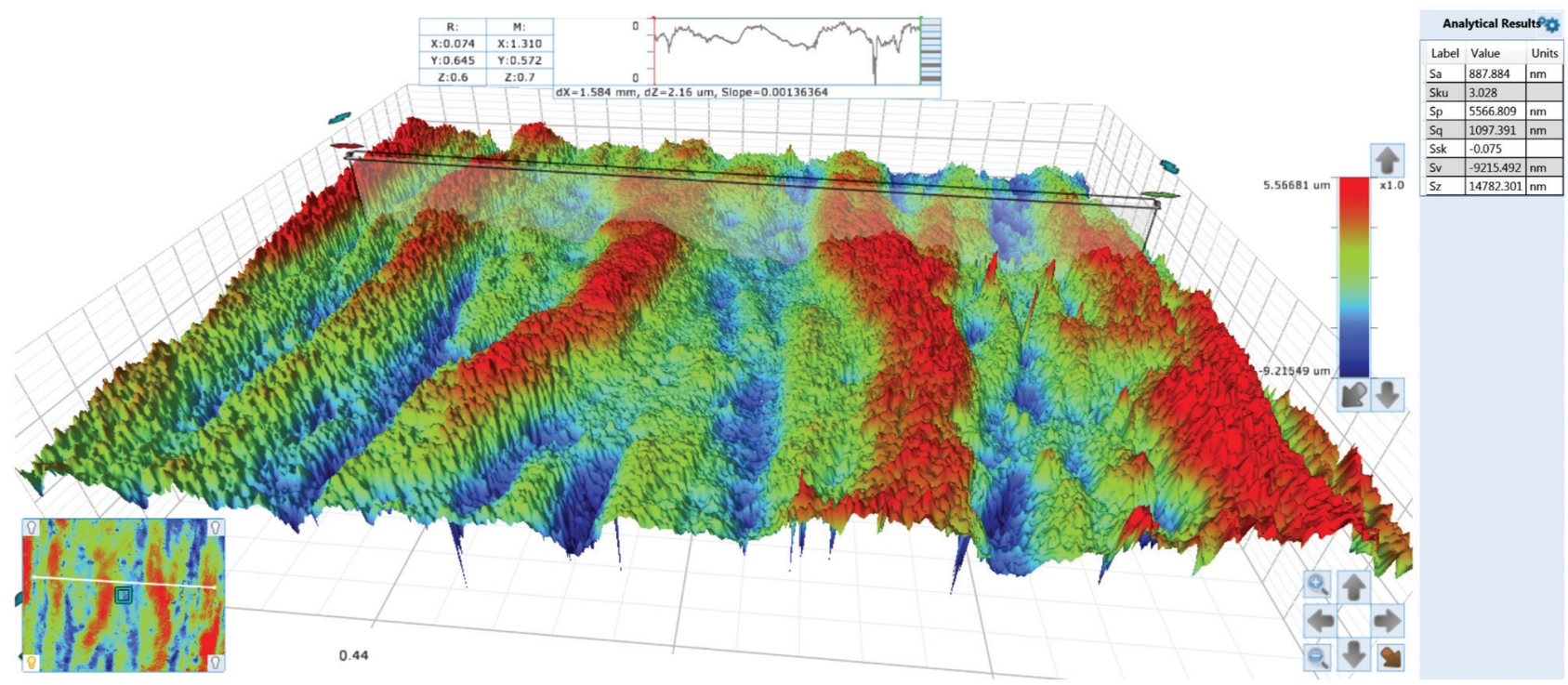

Rys. 2. Obraz 3D chropowatości powierzchni papieru powlekanego błyszczącego z lakierem 2

Fig. 2. 3D image of the surface roughness of coated glossy paper with varnish number 2

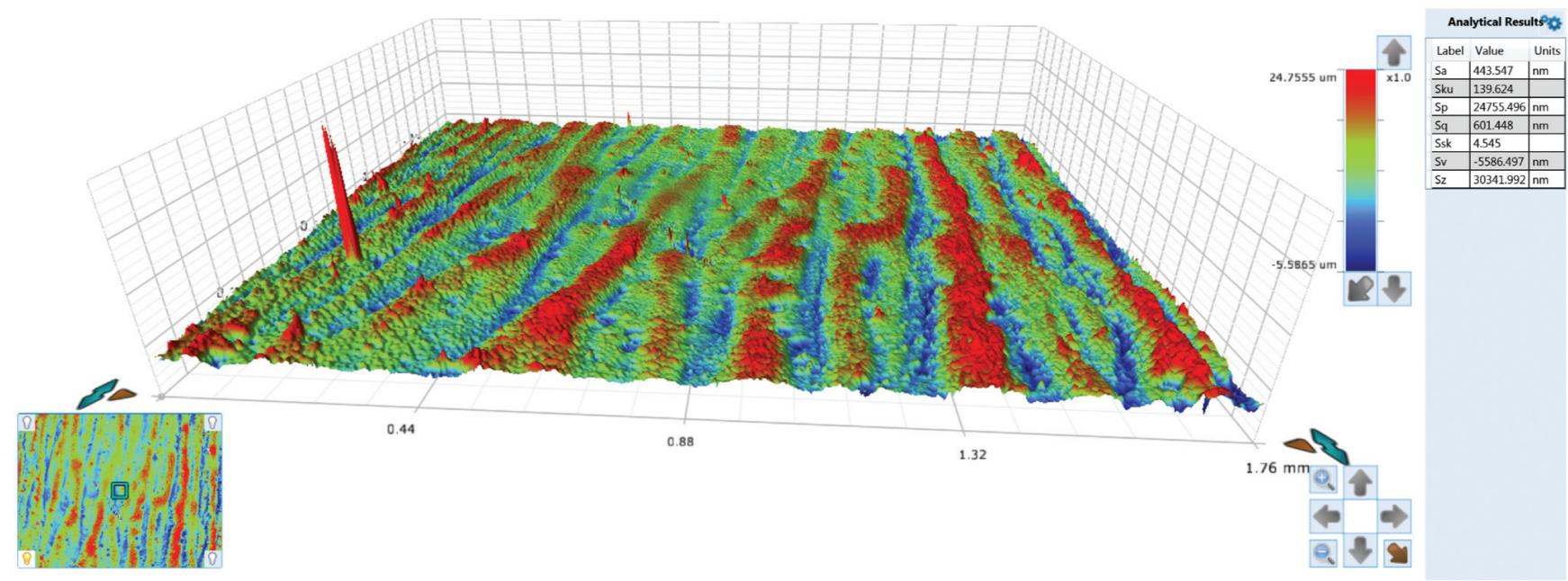

Rys. 3. Obraz 3D chropowatości powierzchni folii PE z lakierem 2

Fig. 3. 3D image of the surface roughness of $P E$ foil with varnish number 2 
jest wynikiem większej wartości napięcia powierzchniowego lakieru w stosunku do wartości napięcia powierzchniowego utwardzonej warstwy farby, jak też wysokich sił kohezyjnych wewnątrz lakieru, co powoduje "ściąganie" się warstwy lakieru, a w konsekwencji tworzenie pofalowanej jego struktury [2]. Papier jest materiałem chłonnym, który łatwiej pokryć farbą czy lakierem. Folia, jako materiał niechłonny należy do trudniej zadrukowywanych materiałów. W celu uzyskania odpowiedniego zwilżenia powierzchni musi być spełniony warunek większego napięcia powierzchniowego materiału zadrukowywanego w stosunku do materiału pokryciowego, jakim jest farba czy lakier. Pofalowana powierzchnia lakieru zaobserwowana została nie tylko na materiale trudnym do zadrukowania, jakim jest folia, ale również na doskonałym materiale drukowym, jakim jest papier. Ta obserwacja potwierdza, że lakier jako materiał lepki nie daje się równomiernie nanieść na podłoże. W pracy użyto trzy różne lakiery o różnej lepkości mierzonej kubkiem Forda. Pofalowana powierzchnia lakieru została zaobserwowana we wszystkich trzech przypadkach.

$\mathrm{Na}$ rysunku 4 zamieszczono wartości współczynnika chropowatości dla niezadrukowanego papieru i folii PE, papieru i folii PE z naniesioną warstwą farby oraz dla wydruków pokrytych farbą, oraz trzema różnymi lakierami. Na podstawie uzyskanych wyników badań można stwierdzić, że w większości przypadków proces lakierowania zwiększa chropowatość powierzchni.

W większym stopniu zjawisko to jest obserwowane w przypadku folii, gdzie dla lakieru 1 zaobserwowano trzykrotny wzrost chropowatości, dla lakieru 3 wzrost tego parametru o ok. 1,7, a w przypadku lakieru 2 o ok. 1,4 razy. Dla podłoża papierowego z naniesioną warstwą lakieru również zaobserwowano wzrost chropowatości, w tym wypadku prawie dwukrotny. W przypadkach pozostałych lakierów wzrost chropowatości nie był tak duży, ale również obserwowany. Zmiany chropowatości oceniono w odniesieniu do niezadrukowanego papieru.

Stwierdzono, że naniesienie farby nie ma tak istotnego znaczenia na strukturę powierzchni jak naniesienie lakieru, co zaobserwowano zarówno dla podłoży papierowych, jak i foliowych.

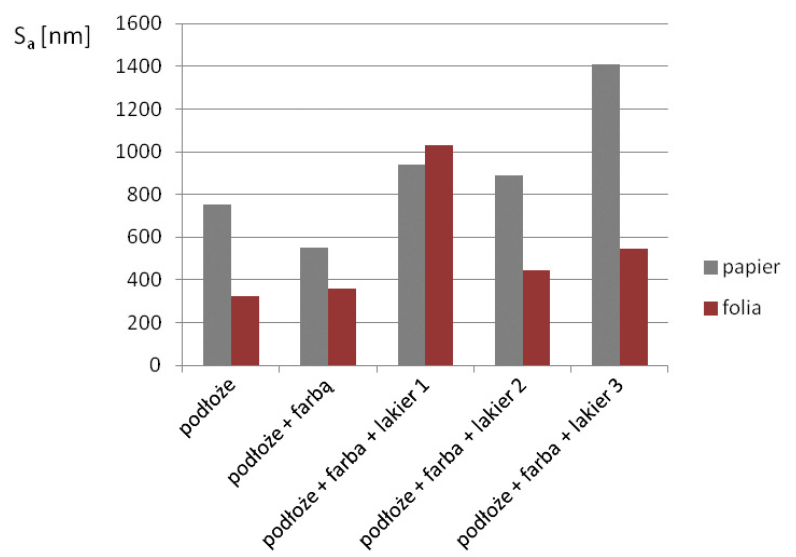

Rys. 4. Współczynnik chropowatości powierzchni podłoża papierowego z farbą i lakierami [1]

Fig. 4. Surface roughness coefficient of paper substrate with ink and varnishes [1]

\section{Dyskusja wyników i wnioski}

Na podstawie wykonanych badań i ich analizy stwierdzono, że proces lakierowania wpływa na wzrost chropowatości powierzchni, co może być spowodowane nierównomiernym ukształtowaniem powierzchni lakieru w wyniku działających sił adhezyjno-kohezyjnych. Lakier nałożony na warstwę farby tworzy pofalowaną powierzchnię. Może być to spowodowane większą wartością napięcia powierzchniowego lakieru w stosunku do wartości napięcia powierzchniowego utwardzonej warstwy farby, co powoduje, że siły kohezyjne działające wewnątrz lakieru powodują utworzenie pofalowanej struktury.

Autorka składa podziękowania Instytutowi Transportu Samochodowego (ITS) za pomoc w badaniach profilometrycznych

\section{Literatura}

[1] Gajadhur M., Steć A.: Improvement of abrasion resistance by overvarnishing in the case of water-based flexographic printing, Journal of Print and Media Technology Research, 2016, 5(1), pp. 15-26.

[2] Gajadhur M., Steć A.: Wpływ lakierowania na właściwości zadrukowanych podłoży papierowych, Przegląd Papierniczy, Warszawa 2018, 74(2), s. 119-23.

[3] Hartus T., Gane P.A.C.: Relating ink solvent-coating component thermal properties to smearing and development of abrasion resistance in ink jet printing, Nordic Pulp and Paper Research Journal, 2012, 27(1), pp. 63-78.

[4] Mesic B., Lestelius M., Engström G.: Printability of PE-coated paperboard with water-borne flexography: Effects of corona treatment and surfactants addition. Pulp and Paper Canada. 2005, 106(11), pp. 36-41.
[5] Mesic B., Engström G., Lestelius M.: Water-borne and solvent-based flexographic inks-influence on uncovered area and ink leveling on PEcoated paperboard. 59th annual technical conference on technical association of the graphic arts, TAGA, march 18, 2007 - march 21, 2007, Pittsburgh, PA, United States: Technical Association of the Graphic Arts, 2007, pp. 631-648.

[6] Rentzhog M., Fogden A.: Print quality and resistance for water-based flexography on polymer-coated boards: Dependence on ink formulation and substrate pretreatment, Progress in Organic Coatings, 2006, 57(3), pp. 183-94. 